\title{
SERTOLI-CELL TUMOUR OF THE TESTIS
}

\author{
MAJOR N. E. CETTI, M.A., F.R.C.S., R.A.M.C. \\ British Military Hospital, Dhekelia*
}

\begin{abstract}
SUMMARY: A case of Sertoli-cell tumour of the testis is described and the literature concerning this rare neoplasm is reviewed.
\end{abstract}

\section{Case report}

A thirty-two year old married school-teacher with two children presented in out-patients in September 1974 with a tender lump in the right testis. He had noticed this lump two months before, following a blow to the testis during a football match. He had no other symptoms and, in particular, had noticed no enlargement of the breasts, loss of libido or of facial or body hair.

General examination revealed a fit young man of normal build. The genitalia were of normal development. The right testis bore a firm, smooth lump adherent to the body of the organ posteriorly, about two centimetres in diameter. The rest of the testis, epididymis and cord felt normal. The left testis was normal. There was no groin lymphadenopathy. Chest X-ray, mid-stream specimen of urine and full blood count were all normal. Hormone assays were not done.

At operation the testis was first inspected via a scrotal incision. This revealed a distinct nodule within the substance of the testis; therefore a standard orchidectomy, ligating and dividing the cord at the deep inguinal ring, was performed through a second incision in the groin.

\section{Pathology}

Macroscopically the testis contained a $2.5 \mathrm{~cm}$ well-demarcated tumour-nodule, soft to firm in consistency, with a slightly bulging cut surface. It was homogeneous and white-tan in colour.

Histologically the tumour was finely encapsulated (Fig. 1) and arisng adjacent to the rete testis. It was composed of a proliferation of rounded, ovoid and spindleshaped cells. These had abundant vacuolated or eosinophilic cytoplasm and were separated into sheets of pseudo-alveolar and pseudo-rosette formations by an abundant acidophilic fibrillary hyaline matrix, supported by a fibro-vascular stroma (Fig. 2). This matrix was focally calcified. There was a vague suggestion in places of an abortive attempt at tubule formation (Fig. 3), but the overall morphology indicated a mesenchymal type of neoplasm with no good evidence of epithelial or organoid differentiation. Individually some of the tumour cells resembled Sertoli cells, but there were no features to suggest Leydig cell origin. The cell nuclei were round, oval or polygonal in shape with a distinct nuclear membrane around a finely distributed chromatin. Nuclear grooves, similar to those seen in ovarian granulosa-cell tumours, were easily discerned (Fig. 4). Call-Exner structures were not found. Occasional mitotic figures were noted. Giant cells were not seen. The seminiferous tubules in

* Now: Queen Elizabeth Military Hospital, Woolwich 
the surrounding testis showed reduced spermato-genesis (Fig. 5). The tumour was well delineated with no breach of the capsule and no evidence of vascular invasion. It was considered to fall into the histologically benign category of the predominantly stromal type of gonadal tumour. The term 'Sertoli-cell/mesenchyme tumour of the

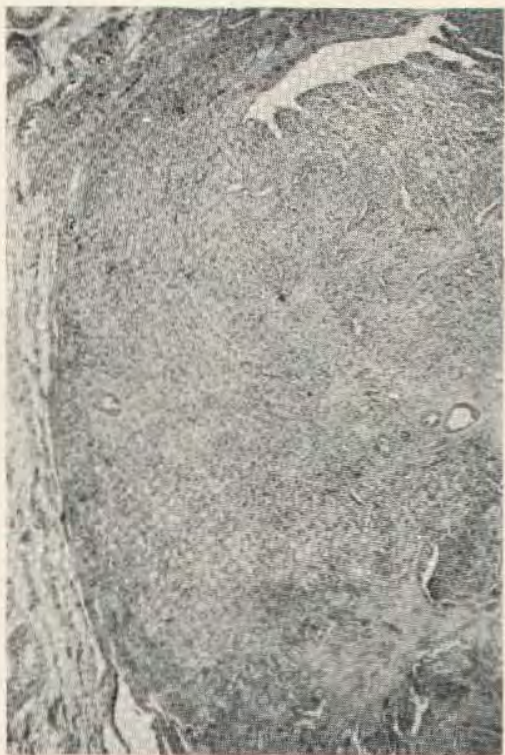

Fig. 1. Encapsulated margin of the tumour $(\mathrm{H} \& \mathrm{E} \times 10)$.

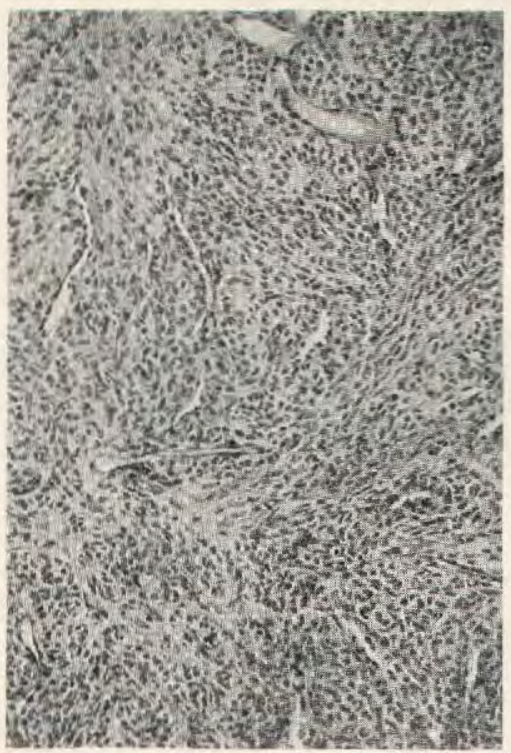

Fig. 3. Abortive tubule formation in parts of the tumour $(\mathrm{H} \& \mathrm{E} \times 40)$.



Fig. 2. General view of the tumour, showing the cellular disposition and fibro-vascular stroma $(\mathrm{H} \& \mathrm{E} \times 40)$.

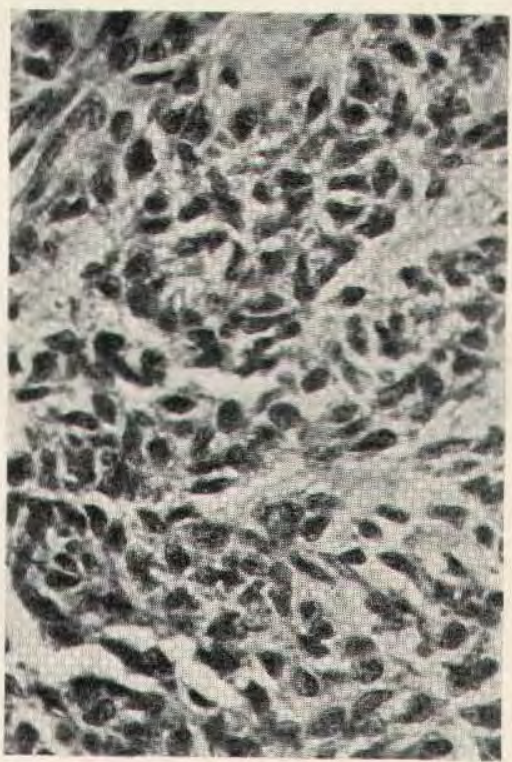

Fig. 4. The nuclear grooves of the tumour cells $(H \& E \times 160)$. 


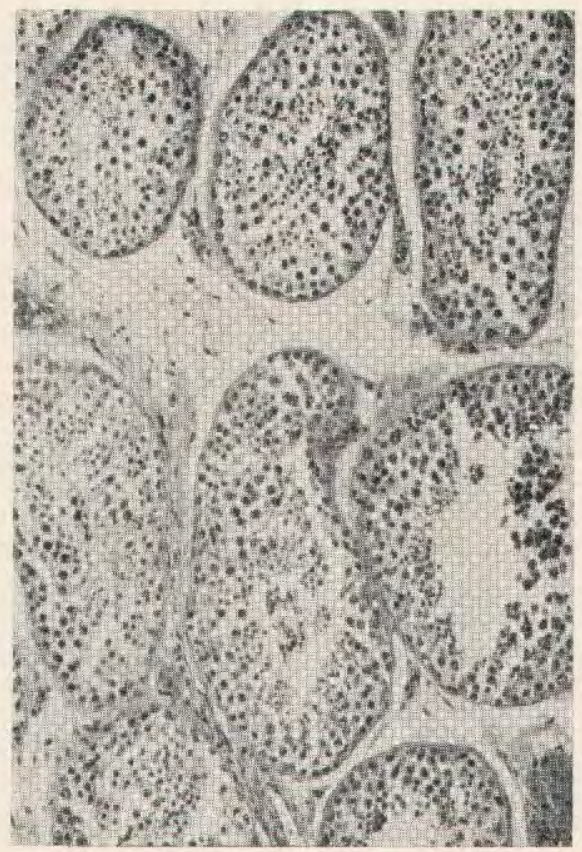

Fig. 5. Reduced spermatogenesis in the surrounding tubules of the affected testis $(H \& E \times 40)$.

testis' is used at present by the British Testicular Tumour Panel to denote this group of tumours of uncertain histogenesis (Symington and Cameron, 1976). Sertoli-cell tumour (Teilum 1958), gonadal stromal tumour (Mostofi, Theiss and Ashley 1959) and androblastoma are alternative names.

The patient has been followed up carefully and after two years there are no overt signs of metastasis.

\section{Discussion}

Tumours of the testis can be divided into two broad categories according to their postulated cells of origin - the germ cells and the supporting or stromal cells. The first category contains the most common tumours in seminoma and teratoma. The tumours of stromal origin are very rare and their study is complicated by variations in terminology, in theories of origin and in reported behaviour.

This group of tumours is said to form 0.4 per cent (Dixon and Moore 1952) and 'less than 2 per cent' (Mostofi and Price 1973) of all testicular tumours. Collins and Symington (1964) found six in a series of 995 testicular tumours and Koppikar and Sirsat (1973) one in a series of 493. The files of the Army Histopathology Registry, which date from 1948, record only one other human Sertoli-cell tumour. Up to 1975 (Trentini and Palmieri) seventy-eight of these tumours had been reported in the English literature.

About one third of the cases occur in the age range 20 to 40 years (Mostofi, Theiss and Ashley 1959), but the tumour has been found in infants (Weitzner and Gropp 1974) and the elderly Abell and Holt (1968). The left testis is affected twice as often as the right (Mostofi and Price 1973). Occurrence in an undescended testicle is described only twice (Kalis and Goulandris 1974, Weitzner and Gropp 1974). 
Feminisation is an oft-quoted feature of these tumours and gynaecomastia is the most common manifestation, which may be unilateral or bilateral. However, the figures on the incidence of gynaecomastia in Sertoli-cell tumour quoted are (Table I).

Table I

Incidence of gynaecomastia in Sertoli-cell tumour

\begin{tabular}{|l|c|}
\hline \multicolumn{1}{|c|}{ Reference } & Incidence \\
\hline Mostofi, Theiss and Ashley 1959 & 9 out of 38 \\
\hline Mostofi and Price 1973, Kalis and Goulandris 1974 & One third of patients \\
\hline Hopkins 1969 & $\begin{array}{c}26 \text { per cent in benign tumours } \\
43 \text { per cent in malignant tumours }\end{array}$ \\
\hline
\end{tabular}

Other evidence of feminisation found is the occasional loss of libido and impotence (Hansen 1975). Hormone assays have been carried out in several of the cases in the reported series and, in some, increased urinary excretion of sex hormones has been demonstrated. However, just as many, or more, have shown absolutely normal hormone levels (Hopkins and Parry 1969) and histological evidence for increased hormone production is also lacking (Mostofi, Theiss and Ashley 1959). It is interesting that Sertoli-cell tumours occur frequently in dogs, where they are associated with high oestrogen levels (Hopkins and Parry 1969).

The histological features are well described by Mostofi and Price (1973). The tumour is usually well circumscribed, encapsulated, greyish-white in colour and one to ten centimetres in diameter. The cell type and organisation are very variable. There may be well-differentiated Sertoli-type cells, hexagonal to tall columnar with large nuclei, arranged in tubules containing debris and eosinophilic precipitate. Other tumours show sheets of spindle-shaped stromal cells or cuboidal cells arranged in follicles. The cell cytoplasm often exhibits vacuoles which contain lipid. Mitoses and giant cells are 'very rare'.

In adults the rest of the involved testis usually shows depressed spermatogenesis, stromal oedema and patchy atrophy of tubules, Mostifi, Theiss and Ashley (1959) postulate that the reduced spermatogenesis is due to the physical presence of the tumour rather than to a possible oestrogenic effect.

The large majority of these tumours is benign. Of the 78 reported nine have matastasised (approximately 12 per cent). Spread is via the iliac and para-aortic lymph nodes and secondaries have been reported in lung, liver and (in one case) multiple osseous sites. If gynaecomastia is a feature of the case, it may regress on removal of the primary tumour and its re-appearance months or years later is suggestive of recurrence or metastasis. As there are no definite histological distinguishing features between benign and malignant Sertoli-cell tumour, except obvious local invasion of tunica, epididymis or capsule, the final diagnosis depends on the occurrence of secondary spread (Talerman, 1971).

It is generally agreed that the treatment of choice is orchidectomy, with radiotherapy and cytotoxic therapy unproven in efficacy (Mostofi, Theiss and Ashley 1959, Hopkins and Parry 1969). 
Careful follow-up is essential in all cases of Sertoli-cell tumour to look for early signs of metastasis and, particularly, to assist in characterizing further this rare and very variable neoplasm.

\section{Acknowledgements}

I wish to thank the staff of the Army Histopathology Registry, Royal Army Medical College, for the pathology report and the photomicrographs.

\section{REFERENCES}

Abell, M. R. and HoltZ, F. (1968). Cancer 21, 852-70.

Collins, D. H. and Symington, T. (1964). Brit. J. Urol. 36, 52 (Suppl.).

Dixon, F. J. and Moore, R. A. (1952). Tumours of the Male Sex Organ. AFIP Fascile 32. P. 120.

HANSEN, G. V. O. (1975). Dan. med. Bull. 22, 33-36.

Hopkins, G. B. and Parry, H. D. (1969). Cancer 23, 463.

Kalis, E. G. and Goulandris, N .D. (1974). J. Urol. 112, 618.

KoppiKaR, D. D. and SirSat, M. V. (1973). Brit. J. Urol. 45, 213.

Mostofi, F. K., Theiss, E. A. and Ashley, D. J. B. (1959). Cancer 12, 944.

Mostofi, F. K. and Price, E. B. (1973). Tumours of the Male Genital System. AFIP Fascile 8. P. 100.

Symington, T. and Cameron, K. M. (1976). Pathology of the Testis. Ed. R. C. B. Pugh. Blackwell Scientific Publications. Oxford.

Talerman, A. (1971). Cancer 28, 446.

Teilum, G. (1958). Cancer 11, 769.

Trentini, G. P. and Palmieri, B. (1975). J. Urol. 113, 725.

Weitzner, S. and Gropp, A. (1974). Amer. J. Dis. Child 128, 541.

\section{Colonel Ethelwald E. Vella, Late R.A.M.C.}

A most extraordinary happening occurred in January 1977 which it is thought might be of interest to readers of the Journal of the Royal Army Medical Corps and the Army Medical Services Magazine, and very possibly of interest to colleagues in the sister medical services.

By a curious set of circumstances five medical journals published papers by Colonel Ethelwald E. Vella (Honorary Assistant Editor of the Journal of the R.A.M.C.) in their January issue :-

1. Paper on Green Monkey Disease: Marburg Virus Disease in the (a) Hospital Up-Date. (b) Up-Date for General Practitioner. (c) Nursing Times.

2. Paper on the Australia Antigen (Hepatitis) in the Nursing Mirror (a reprint from the Hospital Life).

3. Quo Vadis? Unde Venis? in the Journal of the R.A.M.C.

This surely must be a record for an army medical officer, or probably for any Service medical officer. It is also possible that it may even be a record for a civilian medical colleague. 